\title{
Clinical Correlation between Plasma Homocysteine Level and Coronary Artery Disease in Indian Patients
}

\author{
R. Ranjith1*, P. Devika² \\ ${ }^{1}$ Department of Cardiology, District Hospital Palakkad, Kerala, India \\ ${ }^{2}$ Department of Pediatrics, Government Medical College Palakkad, Kerala, India \\ Email: *drranjithrnambiar@gmail.com
}

How to cite this paper: Ranjith, R. and Devika, P. (2017) Clinical Correlation between Plasma Homocysteine Level and Coronary Artery Disease in Indian Patients. World Journal of Cardiovascular Diseases, 7, 477-485.

https://doi.org/10.4236/wjcd.2017.712047

Received: November 11, 2017

Accepted: December 23, 2017

Published: December 26, 2017

Copyright $\odot 2017$ by authors and Scientific Research Publishing Inc. This work is licensed under the Creative Commons Attribution International License (CC BY 4.0).

http://creativecommons.org/licenses/by/4.0/

\begin{abstract}
Objective: The aim of this study was to evaluate correlation between plasma homocysteine and coronary artery disease (CAD) in Indian patients. Methods: This study included 150 patients, 100 subjects in study group with angiographically diagnosed CAD and 50 subjects in control group with a normal coronary angiogram. In the study group, patients were divided into three subgroups viz.: CAD only, CAD with hypertension and CAD with type $2 \mathrm{di}$ abetes mellitus. Plasma homocysteine, lipid profile and other risk factors were compared. Results: Mean homocysteine levels in study group (38.34 \pm 15.25 $\mu \mathrm{mol} / \mathrm{L})$ were significantly higher $(\mathrm{p}<0.01)$ than control group $(9.41 \pm 4.22$ $\mu \mathrm{mol} / \mathrm{L})$. No association was found between homocysteine level and conventional risk factors. Furthermore, no significant correlation was found between plasma homocysteine and lipid components in different groups of patients. Conclusion: The study demonstrated that increased levels of homocysteine are independently related to CAD. However, further studies involving a larger sample size will be required to substantiate the findings of the current study.
\end{abstract}

\section{Keywords}

Homocysteine, Coronary Artery Disease, Risk Factors

\section{Introduction}

Coronary artery disease (CAD) has become a major public health problem in many countries. According to the World Health Organization, CAD is the most common cause of death throughout the world [1]. India has been reported to have the highest prevalence of CAD [2]. The major cardiovascular risk factors are high plasma LDL (low-density lipoprotein), low plasma HDL (high-density 
lipoprotein), smoking, hypertension, diabetes, obesity and physical inactivity. An increased level of LDL is related to the development of atherosclerotic cardiovascular disease, which is the primary pathological basis of CAD [3] [4]. So, the role of newer emerging risk factors is being recognized especially homocysteine, fibrinogen, and lipoprotein.

Homocysteine is a nonprotein amino acid derived from methionine metabolism. Homocysteine converts to cysteine as a result of trans-sulfuration pathway; each pathway depends on series of biochemical enzymes such as cystathionine $\beta$ synthase and methylene tetrahydrofolate reductase (MTHFR) as well as on vitamin B12 and folic acid [5]. The formation of methylene-tetrahydrofolate is catalyzed by MTHFR enzyme which has an effect on the remethylation of homocysteine and these actions depend on vitamin B12 [6]. Molecular deficiency in each of these enzymes can cause hyperhomocysteinemia. Several studies discovered that homocysteine levels are associated with a novel risk factor for CAD and premature atherosclerosis [7]. However, the mechanism of atherosclerosis plaques correlated with hyperhomocysteinemia is not clearly stated. Some studies reported that the effect of hyperhomocysteinemia is associated with increased thrombogenicity, an increase of platelet aggregation, reduction of protein $\mathrm{C}$ activation, oxidative damage of LDL, and endothelial dysfunction [8]. Hyperhomocysteinemia may lead to enhancement adverse effects of risk factors, lipoprotein metabolism, and development of inflammation [9]. The factors which influence the level of homocysteine may vary significantly in a population with age, genetics, and nutrition [10]. Elevated homocysteine levels are associated with some factor including increasing age, male sex, smoking, coffee consumption, high blood pressure, lipid profile, high creatinine and improper diet [7]. Low folate and vitamin B12 are related with elevated homocysteine levels [11]. The incidence of homocysteine levels is altered in ethnic groups due to different genetic conditions, nutritional factors (vitamin deficiency and folic acid deficiency) and lifestyle behaviors [12]. Therefore, the present study was undertaken to examine a possible relationship between plasma homocysteine level and coronary artery disease in Indian patients.

\section{Materials and Methods}

\subsection{Study Design}

The present study was conducted for a period of 1 year from October 2015 and October 2016 in the cardiology department, District hospital Palakkad, Kerala. The patients who subsequently underwent first elective coronary angiography and plasma homocysteine assessments were considered in this study. The present study included 150 patients, 100 subjects in study group with angiographically diagnosed CAD and 50 subjects in control with a normal coronary angiogram. Subjects in the study group were divided into three subgroups viz.: CAD only, CAD with hypertension and CAD with type 2 diabetes mellitus (DM).

Elective coronary angiograms were done at least two weeks following an acute 
coronary event. Indications for coronary angiography were: 1) evaluation of ischemic heart disease or cardiomyopathy and 2) before coronary artery bypass grafting 3) aortic or valvular heart disease surgery or further preoperative investigation in patients with family history of CAD and positive noninvasive test results. Written informed consent was procured from every patient. Angiographic SYNTAX scorings were performed by observers blinded to plasma homocysteine measurements. The inclusion criteria for the study group were: 100 subject having $\geq 50 \%$ luminal narrowing in arteries, having $\geq 1.5 \mathrm{~mm}$ width in coronary artery or its major branch. 50 subjects in control were matched by age and sex individuals who had a normal coronary angiogram. Although the inclusion criteria included all age group, patients were aged above 37 years, absence of any acute disease and informed consent granted.

Patients having hypertensive emergencies, hepatic disease, renal disease, stroke, hypothyroidism, pregnancy and taking any other drugs like methotrexate, carbamaze-pine, phenytoin, theophylline or any form of vitamin supplementation were excluded from this study. All patients undergoing coronary angiography immediately following acute coronary events and all hemodynamically unstable patients were excluded from the study.

After obtaining informed consent, selected cases were subjected to detailed history, laboratory test and imaging studies like ECG, fundoscopy, Echocardiography, blood sugar, hemoglobin $\mathrm{A}_{1} \mathrm{c}$, lipid profile, complete blood count and other routine examinations.

\subsection{Estimation of Plasma Homocysteine}

Plasma homocysteine was estimated using ADVIA Centaur Homocysteine Assay (ADVIA Centaur XP Immunoassay System) which is a one-step competitive immunoassay employing direct Chemiluminescence to measure total homocysteine in EDTA plasma or serum quantitatively.

\subsection{Statistical Analysis}

Statistical analysis was performed using Student's t-test for paired samples using SPSS v.21.0. Values were expressed as a mean \pm standard deviation or as percentages. A p value $<0.05$ was considered statistically significant.

\section{Results}

The age of the patients ranges between 37 and 77 years. Among 150 patients, 105 (70\%) were males, and $45(30 \%)$ were females. In the study group, 75 cases (75\%) were males and 25 cases (25\%) were females (Table 1). Plasma homocysteine levels were significantly higher in females than males in both the study and control groups $(\mathrm{p}<0.001)$. Plasma homocysteine level in study group $(38.34$ $\pm 15.25)$ was significantly higher than a control group $(9.41 \pm 4.22)(\mathrm{p}<0.001)$

[Table 2]. However, there was a significant increase in plasma homocysteine levels in group I: $36.760 \pm 14.77 \mu \mathrm{mol} / \mathrm{L}$, group II: $42.48 \pm 18.99 \mu \mathrm{mol} / \mathrm{L}$, group III: 
Table 1. Plasma homocysteine levels in study and control group.

\begin{tabular}{ccccccc}
\hline Parameter & Sex & $\mathrm{n}=100$ & $\begin{array}{c}\text { Study group } \\
(\text { Mean } \pm \mathrm{SD})\end{array}$ & $\mathrm{n}=50$ & $\begin{array}{c}\text { Control group } \\
(\text { Mean } \pm \text { SD) }\end{array}$ & p value \\
\hline Homocysteine $(\mu \mathrm{mol} / \mathrm{L})$ & Male & 75 & $36.38 \pm 15.04$ & 30 & $9.55 \pm 1.19$ & $<0.001$ \\
& Female & 25 & $44.2 \pm 10.07$ & 20 & $9.10 \pm 0.59$ & \\
\hline
\end{tabular}

Table 2. Comparison of plasma homocysteine level in different study and control group.

\begin{tabular}{cccc}
\hline Group & $\mathrm{n}=150$ & Homocysteine $(\mu \mathrm{mol} / \mathrm{L})$ Mean $\pm \mathrm{SD}$ & $\mathrm{p}$ value \\
\hline Study group & 100 & $38.34 \pm 15.25$ & 0.001 \\
Control group & 50 & $9.41 \pm 4.22$ & \\
Group-I: CAD alone & 45 & $36.76 \pm 14.77$ & 0.05 \\
Control without Hypertension/DM & 32 & $9.15 \pm 1.00$ & \\
Group-II: CAD with Hypertension & 30 & $42.48 \pm 18.99$ & 0.05 \\
Control with Hypertension & 10 & $9.45 \pm 4.93$ & \\
Group-III: CAD with Type 2 DM & 25 & $40.35 \pm 17.72$ & 0.05 \\
Control with DM & 8 & $9.03 \pm 2.17$ & \\
\hline
\end{tabular}

CAD—Coronary artery disease, DM-Diabetes mellitus.

Table 3. Characteristics of homocysteine in patients with conventional risk factors.

\begin{tabular}{cccc}
\hline Conventional risk factors & $\mathrm{n}=100$ & Homocysteine $(\mu \mathrm{mol} / \mathrm{L})$ Mean $\pm \mathrm{SD}$ & $\mathrm{p}$ value \\
\hline Hypertensives & 30 & $42.76 \pm 17.77$ & 0.10 \\
Non-Hypertensives & 70 & $41.36 \pm 15.20$ & \\
Diabetics & 25 & $40.35 \pm 17.72$ & 0.33 \\
Non-Diabetics & 75 & $41.43 \pm 15.20$ & \\
Smokers & 60 & $43.32 \pm 11.32$ & 0.31 \\
Non Smokers & 40 & $44.22 \pm 7.20$ & \\
Alcoholics & 25 & $39.32 \pm 11.72$ & 0.21 \\
Non Alcoholics & 75 & $40.86 \pm 15.28$ & \\
\hline
\end{tabular}

$40.357 \pm 17.72 \mu \mathrm{mol} / \mathrm{L}$ as compared to that of a control group $(\mathrm{p}<0.05)$, as shown in Table 2.

In our study, there was no significant statistical difference between plasma homocysteine level in study group with hypertensives and non-hypertensives $(42.760 \pm 17.77 \mu \mathrm{mol} / \mathrm{L}, 41.360 \pm 15.203 \mu \mathrm{mol} / \mathrm{L}$, respectively, $\mathrm{p}=0.10)$ [Table 3]. Although, there was no significant difference between homocysteine level in study group with diabetics and non-diabetics $(40.357 \pm 17.72 \mu \mathrm{mol} / \mathrm{L}, 41.430 \pm$ $15.203 \mu \mathrm{mol} / \mathrm{L}$, respectively, $\mathrm{p}=0.33$ ) [Table 3]. In addition, there was no significant of mean homocysteine level difference between smokers and nonsmokers $(43.329 \pm 11.32 \mu \mathrm{mol} / \mathrm{L}, 44.229 \pm 7.20 \mu \mathrm{mol} / \mathrm{L}$, respectively, $\mathrm{p}=0.31)$. Furthermore, the mean homocysteine level of alcoholics and non-alcoholics are $39.327 \pm 11.72$ and $40.860 \pm 15.28$, respectively. There was no significant correlation between the average of two groups $(\mathrm{p}=0.21)$. 
Table 4. Lipid profile parameters in different study and control group.

\begin{tabular}{lccccc}
\hline \multicolumn{1}{c}{ Group } & $\mathrm{n}=150$ & $\begin{array}{c}\text { Serum TC } \\
(\mathrm{mg} / \mathrm{dL})\end{array}$ & $\begin{array}{c}\text { Serum TG } \\
(\mathrm{mg} / \mathrm{dL})\end{array}$ & $\begin{array}{c}\text { Serum HDL } \\
(\mathrm{mg} / \mathrm{dL})\end{array}$ & $\begin{array}{c}\text { Serum LDL } \\
(\mathrm{mg} / \mathrm{dL})\end{array}$ \\
\hline $\begin{array}{l}\text { Control group } \\
\text { Group-I: CAD alone }\end{array}$ & 50 & $172.08 \pm 26.80$ & $100.88 \pm 18.26$ & $47.51 \pm 14.53$ & $110.29 \pm 24.79$ \\
$\begin{array}{l}\text { Group-II: CAD with } \\
\text { Hypertension }\end{array}$ & 30 & $215.73 \pm 8.56^{*}$ & $152.28 \pm 66.36^{*}$ & $41.78 \pm 4.63^{* *}$ & $139.73 \pm 37.04^{*}$ \\
$\begin{array}{l}\text { Group-III: CAD with } \\
\text { Type 2 DM }\end{array}$ & 25 & $184.23 \pm 7.12$ & $132.07 \pm 49.16^{* *}$ & $45.09 \pm 16.07$ & $95.60 \pm 40.46$ \\
\hline $\begin{array}{l}\text { CAD-Coronary artery disease, TC-Total cholesterol, TG-Triglyceride, HDL-High density lipoprotein, } \\
\text { LDL-Low density lipoprotein. Values are given as mean } \pm \text { S.D. Different study group compared with con- } \\
\left.\text { trol subjects. }{ }^{*} \mathrm{p}<0.05,{ }^{* *} \mathrm{p}<0.001\right) .\end{array}$ &
\end{tabular}

Table 5. Correlation between homocysteine and lipid profile parameters

\begin{tabular}{cccccccc}
\hline & Group-I: Hypertension & $\begin{array}{c}\text { Group-II: } \\
\text { Hypertension } \\
\text { with CAD }\end{array}$ & $\begin{array}{c}\text { Group-III: } \\
\text { Hypertension } \\
\text { with Type 2 DM }\end{array}$ \\
\cline { 2 - 7 } & $\mathrm{r}$ & $\mathrm{p}$ & $\mathrm{r}$ & $\mathrm{p}$ & $\mathrm{r}$ & $\mathrm{p}$ \\
\hline Homocysteine vs TC & -0.053 & 0.25 & -0.055 & 0.76 & -0.083 & 0.66 \\
Homocysteine vs TG & -0.008 & 0.96 & -0.009 & 0.91 & 0.053 & 0.77 \\
Homocysteine vs LDL & -0.055 & 0.28 & -0.065 & 0.82 & -0.080 & 0.70 \\
Homocysteine vs HDL & 0.219 & 0.21 & 0.221 & 0.23 & 0.196 & 0.17 \\
\hline TC-Total cholesterol, TG-Triglyceride, LDL-Low density lipoprotein, HDL-High density lipoprotein.
\end{tabular}

The lipid profile changes in control and subgroups of patients are shown $\mathrm{Ta}$ ble 4. The levels of total cholesterol, triglyceride, and LDL cholesterol were significantly higher in group-II $(\mathrm{p}<0.001)$ as compared with control group. Moreover, group-II patients had significantly decreased $(p<0.05)$ HDL cholesterol level than control group. Group-I showed significant variation $(p<0.05)$ in the levels of total cholesterol, and LDL cholesterol as compared with control. Also, group-III showed a significant increase $(\mathrm{p}<0.05)$ in triglyceride level as compared with control. The correlations between homocysteine and lipid profile parameters are shown " $r$ " (coefficient of correlation) and "p" value in different groups of patients (Table 5). There was no significant correlation between plasma homocysteine and lipid components in different group patients. The plasma homocysteine levels are represented in Figure 1.

\section{Discussion}

Homocysteine has been projected as a novel risk factor for CAD [13]. Some researchers embarked upon the mission to show plasma homocysteine as an independent risk factor for CAD. Some studies reported that correlation between high plasma homocysteine and atherothrombotic vascular disease in patients [14] [15] [16]. In this study, we demonstrated the relationship between plasma 


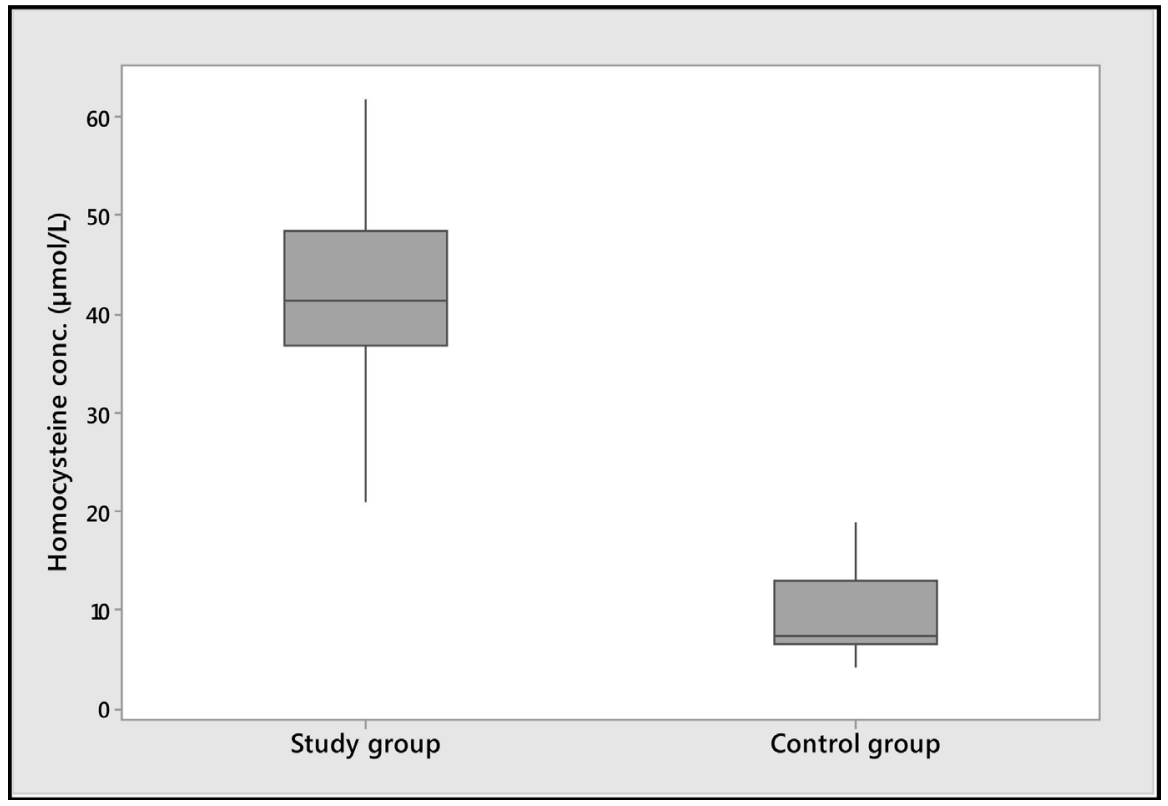

Figure 1. Plasma homocysteine levels in study and control group.

homocysteine level and CAD in Indian patients. Most prospective and retrospective studies have demonstrated that high homocysteine is an independent risk factor for CAD [7]. Previous studies have shown that high rates of CAD in Asian Indians are associated by high prevalence of conventional risk factors such as hypercholesterolemia, hypertension, and smoking [4]. Furthermore, the finding of $36.387 \pm 15.04 \mu \mathrm{mol} / \mathrm{L}$ in male and $44.2 \pm 10.07 \mu \mathrm{mol} / \mathrm{L}$ in female reflects a higher level of plasma homocysteine in females with CAD. Mean homocysteine levels in study group were significantly higher $(\mathrm{p}<0.001)$ than the control group. Abraham et al. and Puri et al. also reported similar observations of plasma homocysteine level higher among study group as compared to control group [4] [13]. This finding is also consistent with western studies undertaken by Verhoef et al. \& Taylor et al. [17] [18]. Most common cause of higher levels plasma homocysteine may be due to a genetic mutation (MTHFR gene) or nutritional factors. According to some studies, MTHFR gene might be associated with hyperhomocysteinemia and CAD in some populations [5] [19] [20] [21]. In this study, plasma homocysteine levels in different groups showed a significant increase $(\mathrm{p}<0.05)$ as compared to control group. In past studies shows that similar assessment on plasma homocysteine abnormality association with hypertension and diabetes mellitus in CAD patients [19] [22] [23].

In a current study, we found no significant correlation between plasma homocysteine level and other conventional risk factors of CAD (hypertension, diabetes mellitus, smoking, and alcohol consumers). These results were similar to those reported in Deepa et al. study [24]. In our study, total serum cholesterol, triglycerides, LDL were significantly higher $(\mathrm{p}<0.001)$ and HDL level significantly lower in the study group compared to control and specifically in group II (CAD with hypertension). We calculated Pearson' correlation coefficient and 
"p" value in different groups for plasma homocysteine levels with lipid profile. Furthermore, there was no significant association between plasma homocysteine and lipid profile. A similar finding has been reported from Puri et al. [4]. This variation may be due to small sample size confounding factors in our study. Higher plasma homocysteine values in our study group indicate that our population subgroups are deficient in folate levels and require folic acid supplementation. This intervention may decrease the premature incidence of CAD and reduce the mortality rate of the population.

\section{Conclusion}

This study indicates that elevated plasma homocysteine is an independent risk factor associated with CAD. Further studies involving a larger sample size will be required to investigate the benefits from vitamin administration in patients with increased homocysteine levels to prevent the premature incidence of CAD.

\section{Conflicts of Interest}

The authors declare no conflicts of interest.

\section{References}

[1] Ghassibe-Sabbagh, M., Platt, D.E., Youhanna, S., et al. (2012) Genetic and Environmental Influences on Total Plasma Homocysteine and Its Role in Coronary Artery Disease Risk. Atherosclerosis, 222, 180-186. https://doi.org/10.1016/j.atherosclerosis.2012.02.035

[2] Gupta, R., Mohan, I. and Narula, J. (2016) Trends in Coronary Heart Disease Epidemiology in India. Annals of Global Health, 82, 307-315. https://doi.org/10.1016/j.aogh.2016.04.002

[3] Roy, S. (2014) Atherosclerotic Cardiovascular Disease Risk and Evidence-Based Management of Cholesterol. The American Journal of the Medical Sciences, 6, 191-198. https://doi.org/10.4103/1947-2714.132916

[4] Puri, A., Gupta, O.K., Dwivedi, R.N., et al. (2003) Homocysteine and Lipid Levels in Young Patients with Coronary Artery Disease. The Journal of the Association of Physicians of India, 51, 681-685.

[5] Schaffer, A., Verdoia, M., Cassetti, E., et al. (2014) Relationship between Homocysteine and Coronary Artery Disease. Results from a Large Prospective Cohort Study. Thrombosis Research, 134, 288-293.

https://doi.org/10.1016/j.thromres.2014.05.025

[6] Marinou, K., Antoniades, C., Tousoulis, D., et al. (2005) Homocysteine: A Risk Factor for Coronary Artery Disease? Hellenic Journal of Cardiology, 46, 59-67.

[7] Shenoy, V., Mehendale, V., Prabhu, K., et al. (2014) Correlation of Serum Homocysteine Levels with the Severity of Coronary Artery Disease. Indian Journal of Clinical Biochemistry, 29, 339-344. https://doi.org/10.1007/s12291-013-0373-5

[8] Bozkurt, E., Keles, S., Acikel, M., et al. (2004) Plasma Homocysteine Level and the Angiographic Extent of Coronary Artery Disease. Angiology, 55, 265-270. https://doi.org/10.1177/000331970405500305

[9] Baszczuk, A. and Kopczynski, Z. (2014) Hyperhomocysteinemia in Patients with 
Cardiovascular Disease. Postepy Higieny I Medycyny Doswiadczalnej (Online), 68, 579-589. https://doi.org/10.5604/17322693.1102340

[10] Faeh, D., Chiolero, A. and Paccaud, F. (2006) Homocysteine as a Risk Factor for Cardiovascular Disease: Should We (Still) Worry About? Swiss Medical Weekly, 136, 745-756.

[11] Anderson, C.A.M., Jee, S.H., Charleston, J., et al. (2010) Effects of Folic Acid Supplementation on Serum Folate and Plasma Homocysteine Concentrations in Older Adults: A Dose-Response Trial. American Journal of Epidemiology, 172, 932-941. https://doi.org/10.1093/aje/kwq197

[12] Guo, S., Pang, H., Guo, H., et al. (2015) Ethnic Differences in the Prevalence of High Homocysteine Levels Among Low-Income Rural Kazakh and Uyghur Adults in Far Western China and Its Implications for Preventive Public Health. International Journal of Environmental Research and Public Health, 12, 5373-5385. https://doi.org/10.3390/ijerph120505373

[13] Abraham, R., John, M.J., Calton, R., et al. (2006) Raised Serum Homocysteine Levels in Patients of Coronary Artery Disease and the Effect of Vitamin B12 and Folate on Its Concentration. Indian Journal of Clinical Biochemistry, 21, 95-100. https://doi.org/10.1007/BF02913073

[14] McCully, K.S. (2015) Homocysteine and the Pathogenesis of Atherosclerosis. Expert Review of Clinical Pharmacology, 8, 211-219. https://doi.org/10.1586/17512433.2015.1010516

[15] McCully, K. (1969) Vascular Pathology of Homocysteinemia: Implications for the Pathogenesis of Arteriosclerosis. American Journal of Pathology, 56, 111-128.

[16] Clarke, R., Daly, L., Robinson, K., et al. (1991) Hyperhomocysteinemia: An Independent Risk Factor for Vascular Disease. The New England Journal of Medicine, 324, 1149-1155. https://doi.org/10.1056/NEJM199104253241701

[17] Verhoef, P., Kok, F.J., Kruyssen, D.A., et al. (1997) Plasma Total Homocysteine, B Vitamins, and Risk of Coronary Atherosclerosis. Arteriosclerosis, Thrombosis, and Vascular Biology, 17, 989-995. https://doi.org/10.1161/01.ATV.17.5.989

[18] Taylor, L.M., Moneta, G.L., Sexton, G.J., et al. (1999) Prospective Blinded Study of the Relationship between Plasma Homocysteine and Progression of Symptomatic Peripheral Arterial Disease. Journal of Vascular Surgery, 29, 8-21. https://doi.org/10.1016/S0741-5214(99)70345-9

[19] Naghshtabrizi, B., Shakerian, F., Hajilooi, M., et al. (2012) Plasma Homocysteine Level and Its Genotypes as a Risk Factor for Coronary Artery Disease in Patients Undergoing Coronary Angiography. Journal of Cardiovascular Disease Research, 3, 276-279. https://doi.org/10.4103/0975-3583.102695

[20] Cortese, C. and Motti, C. (2001) MTHFR Gene Polymorphism, Homocysteine and Cardiovascular Disease. Public Health Nutrition, 4, 493-497.

https://doi.org/10.1079/PHN2001159

[21] Nishi, A., Numata, S., Tajima, A., et al. (2014) Meta-Analyses of Blood Homocysteine Levels for Gender and Genetic Association Studies of the MTHFR C677T Polymorphism in Schizophrenia. Schizophrenia Bulletin, 40, 1154-1163. https://doi.org/10.1093/schbul/sbt154

[22] Nygård, O., Nordrehaug, J.E., Refsum, H., et al. (1997) Plasma Homocysteine Levels and Mortality in Patients with Coronary Artery Disease. New England Journal of Medicine, 337, 230-237. https://doi.org/10.1056/NEJM199707243370403

[23] Refsum, H., Ueland, P., Nygård, O., et al. (1998) Homocysteine and Cardiovascular Disease. Annual Review of Medicine, 49, 31-62. 
https://doi.org/10.1146/annurev.med.49.1.31

[24] Deepa, R., Velmurugan, K., Saravanan, G., et al. (2001) Absence of Association between Serum Homocysteine Levels and Coronary Artery Disease in South Indian Males. The Indian Heart Journal, 53, 44-47. 